University of Wollongong

Research Online

Australian Institute for Innovative Materials -

Papers

Australian Institute for Innovative Materials

$1-1-2010$

\title{
Lead-free potassium bismuth titanate thin film with complex Aurivillius layer structure
}

\author{
Zhenxiang Cheng \\ University of Wollongong, cheng@uow.edu.au \\ Xiaolin Wang \\ University of Wollongong, xiaolin@uow.edu.au \\ Hongyang Zhao \\ National Institute Materials Science, Japan \\ Hideo Kimura \\ National Institute For Materials Science
}

Follow this and additional works at: https://ro.uow.edu.au/aiimpapers

Part of the Engineering Commons, and the Physical Sciences and Mathematics Commons

\footnotetext{
Research Online is the open access institutional repository for the University of Wollongong. For further information
} contact the UOW Library: research-pubs@uow.edu.au 


\title{
Lead-free potassium bismuth titanate thin film with complex Aurivillius layer structure
}

\author{
Abstract \\ A ferroelectric thin film of Aurivillius phase $\mathrm{K}_{0.5} \mathrm{Bi}_{4.5} \mathrm{Ti}_{4} \mathrm{O}_{15}(\mathrm{KBT})$ with a complex bismuth layer-structure \\ was fabricated using the pulsed laser deposition method. The thin film grown on $\mathrm{Pt} / \mathrm{Ti} / \mathrm{SiO}_{2} / \mathrm{Si}$ substrate \\ shows a strong c-axis orientation, as revealed by $\mathrm{x}$-ray diffraction results, and platelike growth of grains. A \\ $\mathrm{Pt} / \mathrm{KBT} / \mathrm{Pt}$ capacitor shows a maximum polarization of about $20 \mu \mathrm{C} / \mathrm{cm}^{2}$. In addition, the capacitor also \\ shows good fatigue resistance, with a decrease of $14.5 \%$ in the remanent polarization after $10^{7}$ switching \\ cycles. This Aurivillius phase with four layers of $\mathrm{TiO}_{6}$ octahedra in its unit cell has a band gap of $3.6 \mathrm{eV}$, \\ which is greater than that of $\mathrm{Bi}_{4} \mathrm{Ti}_{3} \mathrm{O}_{12}$. \\ Keywords \\ Lead, free, potassium, bismuth, titanate, thin, film, complex, Aurivillius, layer, structure \\ Disciplines \\ Engineering | Physical Sciences and Mathematics \\ Publication Details \\ Cheng, Z, Wang, P, Zhao, H, \& Kimura, H (2010), Lead-free potassium bismuth titanate thin film with \\ complex Aurivillius layer structure, Journal of Applied Physics, 107(8), pp. 084105-1-084105-4.
}

This journal article is available at Research Online: https://ro.uow.edu.au/aiimpapers/93 


\title{
Lead-free potassium bismuth titanate thin film with complex Aurivillius layer structure
}

\author{
Z. X. Cheng, ${ }^{1, a)}$ X. L. Wang, ${ }^{1}$ H. Y. Zhao, ${ }^{2}$ and H. Kimura ${ }^{2}$ \\ ${ }^{1}$ Institute for Superconducting and Electronic Materials, Faculty of Engineering, University of Wollongong, \\ Innovation Campus, Squires Way, Fairy Meadow, NSW 2519, Australia \\ ${ }^{2}$ National Institute for Material Science, Sengen 1-2-1, Tsukuba, Ibaraki 305-0047, Japan
}

(Received 12 October 2009; accepted 7 March 2010; published online 21 April 2010)

\begin{abstract}
A ferroelectric thin film of Aurivillius phase $\mathrm{K}_{0.5} \mathrm{Bi}_{4.5} \mathrm{Ti}_{4} \mathrm{O}_{15}$ (KBT) with a complex bismuth layer-structure was fabricated using the pulsed laser deposition method. The thin film grown on $\mathrm{Pt} / \mathrm{Ti} / \mathrm{SiO}_{2} / \mathrm{Si}$ substrate shows a strong $c$-axis orientation, as revealed by $\mathrm{x}$-ray diffraction results, and platelike growth of grains. A Pt/KBT/Pt capacitor shows a maximum polarization of about $20 \mu \mathrm{C} / \mathrm{cm}^{2}$. In addition, the capacitor also shows good fatigue resistance, with a decrease of $14.5 \%$ in the remanent polarization after $10^{7}$ switching cycles. This Aurivillius phase with four layers of $\mathrm{TiO}_{6}$ octahedra in its unit cell has a band gap of $3.6 \mathrm{eV}$, which is greater than that of $\mathrm{Bi}_{4} \mathrm{Ti}_{3} \mathrm{O}_{12}$. (C) 2010 American Institute of Physics. [doi:10.1063/1.3374709]
\end{abstract}

\section{INTRODUCTION}

Aurivillius phase bismuth layer-structured titanate materials have been attracting great attention in recent years from both the theoretical and applications points of view. ${ }^{1-5}$ Many materials in this family show excellent ferroelectric and piezoelectric properties. For example, $\mathrm{Sm}$ modified $\mathrm{Bi}_{4} \mathrm{Ti}_{3} \mathrm{O}_{12}$ shows a high Curie temperature $\left(\mathrm{T}_{\mathrm{C}} \approx 675^{\circ} \mathrm{C}\right)$, large spontaneous polarization $\left(\mathrm{P}_{\mathrm{s}} \approx 38 \mu \mathrm{C} / \mathrm{cm}^{2}\right)$, and $\mathrm{ex}-$ cellent fatigue resistance $\left(>10^{9}\right.$ switching cycles), which has great potential in applications in nonvolatile ferroelectric random access memory devices. Due to its lead-free nature, it is also a candidate as an environmentally friendly piezoelectric material (piezoelectric tensor element, $\mathrm{d}_{33} \approx 20$ $\left.\times 10^{-12} \mathrm{C} / \mathrm{N}\right)^{6,7}$

In the crystal structure of the bismuth layer-structured ferroelectrics, perovskite blocks $\left(\mathrm{A}_{\mathrm{m}-1} \mathrm{~B}_{\mathrm{m}} \mathrm{O}_{3 \mathrm{~m}+1}, \mathrm{~A}=\mathrm{Bi}, \mathrm{B}\right.$ $=\mathrm{Ti}, \mathrm{Nb}, \mathrm{Ta}$ ) composed of $\mathrm{m}$ layers of $\mathrm{BO}_{6}$ octahedra, with A-site cations occupying the holes created by the octahedra, are sandwiched between $\mathrm{Bi}_{2} \mathrm{O}_{2}$ layers, which is suggested to be the structural reason for the excellence of the ferroelectric performance of this family of materials. ${ }^{8,9}$ Besides $\mathrm{Bi}_{4} \mathrm{Ti}_{3} \mathrm{O}_{12}$ and its derivatives with three layers of $\mathrm{TiO}_{6}$ octahedra, $\mathrm{SrBi}_{2} \mathrm{Ta}_{2} \mathrm{O}_{9}$ is another kind of bismuth layer-structured ferroelectric material with $\mathrm{m}=2$ that shows excellent ferroelectric properties, which have been well studied. ${ }^{8,10}$ In comparison to the volume of work that has been done on the above two systems with $m=2$ and 3 , there is still a great deal of work that should be done on those Aurivillius phase bismuth layerstructured ferroelectrics with $\mathrm{m}=4$. For example, although some ferroelectrics in this family of materials, such as $\mathrm{ABi}_{4} \mathrm{Ti}_{4} \mathrm{O}_{15}(\mathrm{~A}=\mathrm{Ca}, \mathrm{Ba}, \mathrm{Sr}$, and $\mathrm{Pb})$, have been studied in the form of thin films, bulk ceramics, and single crystals, one of its derivatives, $\mathrm{M}_{0.5} \mathrm{Bi}_{4.5} \mathrm{Ti}_{4} \mathrm{O}_{15}(\mathrm{M}=\mathrm{Na}$ and $\mathrm{K})$ has only been studied in ceramic and single crystal forms. ${ }^{11-15}$ Results on the single crystals have shown that $\mathrm{K}_{0.5} \mathrm{Bi}_{4.5} \mathrm{Ti}_{4} \mathrm{O}_{15}(\mathrm{KBT})$ has a large remanent polarization of $31 \mu \mathrm{C} / \mathrm{cm}^{2}$, which sug-

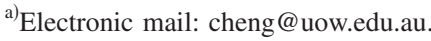

gests that it has the largest spontaneous polarization among the $\mathrm{m}=4$ bismuth layer-structured ferroelectrics. However, there have been no reports regarding to the fabrication and properties of its thin film form, probably due to the difficulty in the fabrication of films containing the two volatile elements bismuth and potassium. Therefore, the successful fabrication of KBT film and its properties are of great interest, as most applications of ferroelectrics will be in their thin film forms. In this letter, a KBT thin film was fabricated by using a pulsed laser deposition (PLD) system, and the ferroelectric and dielectric properties of a prototype memory device, a $\mathrm{Pt} / \mathrm{KBT} / \mathrm{Pt}$ capacitor, were characterized.

\section{EXPERIMENTAL DETAILS}

The target for the PLD deposition was fabricated by the standard solid state reaction method. Powders of $\mathrm{K}_{2} \mathrm{CO}_{3}$, $\mathrm{Bi}_{2} \mathrm{O}_{3}$, and $\mathrm{TiO}_{2}$, with high purity of $99.99 \%$, were used as the starting materials. The appropriate amount of each starting chemical was prepared based on the element ratio in the KBT formula, with $5 \%$ extra bismuth to compensate for the evaporation loss of volatile bismuth during the deposition process. The chemicals were well mixed by grinding and then pressed into a pellet. This was followed by a heattreatment at $800{ }^{\circ} \mathrm{C}$ for $10 \mathrm{~h}$. Then, the reacted product was ground, pressed into a pellet, and sintered at the higher temperature of $950{ }^{\circ} \mathrm{C}$ for $2 \mathrm{~h}$. The sintered material was then used as the target. Third harmonic generation of a Nd:yttrium aluminum garnet laser with a wavelength of $355 \mathrm{~nm}$ and a repetition rate of $10 \mathrm{~Hz}$ was used as the laser source. The thin films were initially deposited on $\mathrm{Pt} / \mathrm{Ti} / \mathrm{SiO}_{2} / \mathrm{Si}$ substrate or fused quartz glass substrate at $620{ }^{\circ} \mathrm{C}$, and then cooled down to room temperature following rapid thermal processing.

The phase and structure of the as-deposited film were determined by $\mathrm{x}$-ray diffraction (XRD) using $\mathrm{Cu} K \alpha$ radiation on a JEOL 3500 XRD machine. The morphology of the films was observed by a Veeco $3000^{\mathrm{TM}}$ scanning probe microscope (SPM) in tapping mode. Pt upper electrodes with an 


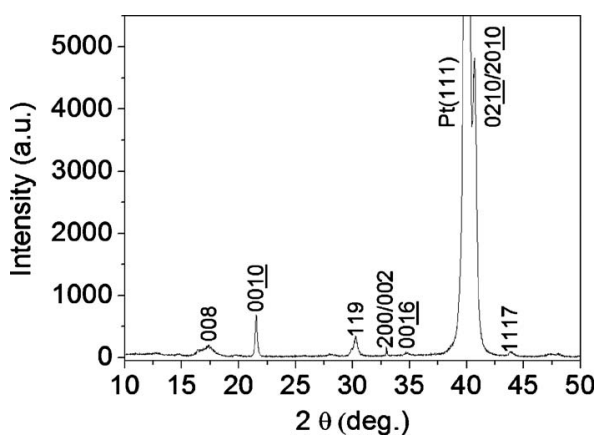

FIG. 1. XRD pattern of the KBT thin film on $\mathrm{Pt} / \mathrm{Ti} / \mathrm{SiO}_{2} / \mathrm{Si}$ substrate fabricated by the PLD method.

area of $0.0314 \mathrm{~mm}^{2}$ were deposited by magnetron sputtering through a metal shadow mask to form a memory device. The thicknesses of the films were measured by observation of the thin film cross-section by scanning electron microscope (SEM). Results show that the thin film sample studied in this report has a thickness of around $500 \mathrm{~nm}$. The ferroelectric properties were measured at room temperature with an aixACCT EASY CHECK 300 ferroelectric tester. The dielectric properties of the memory capacitor were measured using an HP4284 LCR meter. An optical transmission measurement was carried out with the thin film sample coated on fused quartz glass by using a Shimadzu UV-3600 spectrophotometer.

\section{RESULTS AND DISCUSSION}

Figure 1 shows the XRD pattern of the KBT thin film fabricated on $\mathrm{Pt} / \mathrm{Ti} / \mathrm{SiO}_{2} / \mathrm{Si}$ substrate by the PLD method. All the diffraction peaks are indexed based on an orthorhombic symmetry with $A 21 \mathrm{am}$ space group and lattice parameters of $a=0.5433 \mathrm{~nm}, b=0.5456 \mathrm{~nm}$, and $c=4.1189 \mathrm{~nm}$. No apparent diffraction peaks from any impurity were observed. Based on the XRD pattern, which features strong diffraction from the $(00 l)$ planes, the fabricated thin films show a very strong growth habit in the $a b$-plane, which is well in accordance with the layered structure along the $c$ direction of this material.

Figure 2 shows the SPM morphology of the fabricated thin films. It is found that the average grain size is around $100 \mathrm{~nm}$. Most of the grains in the thin films appear sheetlike, which clearly indicates a special orientation of the thin film and its growth habit on the $\mathrm{Pt} / \mathrm{Ti} / \mathrm{SiO}_{2} / \mathrm{Si}$ substrate. Also, the layer structure can be observed if a particular grain with growth steps on it is observed, showing a layer-by-layer growth mechanism.

In Fig. 3, the polarization-electrical field (P-E) loops of a memory element $\mathrm{Pt} / \mathrm{KBT} / \mathrm{Pt}$ capacitor measured at $100 \mathrm{~Hz}$ show that the maximum polarization is about $20 \mu \mathrm{C} / \mathrm{cm}^{2}$ at a maximum polarization electric field just below the breakdown voltage. Saturated polarization was not successfully detected because a higher voltage would destroy the sample. The sensing margin of $2 \mathrm{P}_{\mathrm{r}}=20 \mu \mathrm{C} / \mathrm{cm}^{2}$, where the remanent polarization, $\mathrm{P}_{\mathrm{r}}$, is the difference between the positive and negative remanent polarizations: $\mathrm{P}_{\mathrm{r}}=\mathrm{P}_{\mathrm{r}}^{+}-\mathrm{P}_{\mathrm{r}}^{-}$. The coercive field is $89 \mathrm{kV} / \mathrm{cm}$ when a maximum voltage is applied during P-E measurements.

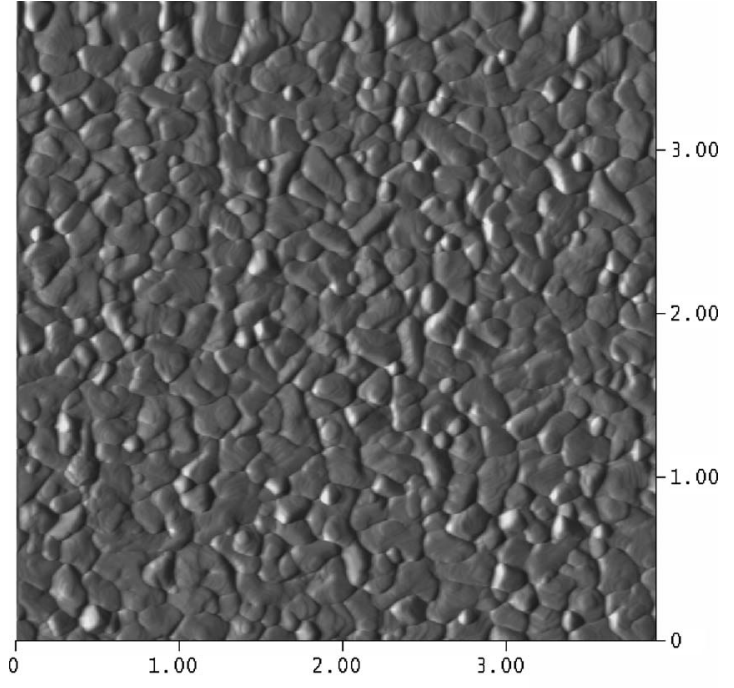

FIG. 2. Tapping mode SPM morphology of the KBT thin films fabricated on $\mathrm{Pt} / \mathrm{Ti} / \mathrm{SiO}_{2} / \mathrm{Si}$ substrate by the PLD method.

The $\mathrm{P}_{\mathrm{r}}$ value of $10 \mu \mathrm{C} / \mathrm{cm}^{2}$ measured from the thin film sample capacitor is much less than the $\mathrm{P}_{\mathrm{r}}$ value of $31 \mu \mathrm{C} / \mathrm{cm}^{2}$ obtained from a single crystal sample. One of the reasons for the difference is the different orientations of the samples in the measurements. For the measurement of the single crystal sample, the applied electrical field was along its $a(b)$-axis. Therefore, the obtained $\mathrm{P}_{\mathrm{r}}$ value is the polarization along the crystal's $a$-axis or $b$-axis. However, as shown by the XRD results, the thin film on the Pt electrode fabricated in this study is highly $c$-axis oriented. Therefore, the observed difference is mainly caused by the sample orientation. This strong orientation dependence of the ferroelectric properties seems to be a common property for most of the bismuth layer-structured ferroelectrics. For example, $\mathrm{Bi}_{4} \mathrm{Ti}_{3} \mathrm{O}_{12}$ also has strongly orientation dependent ferroelectric properties, with a $2 \mathrm{P}_{\mathrm{r}}$ value of $5 \mu \mathrm{C} / \mathrm{cm}^{2}$ for highly $c$-axis oriented thin film and a $2 \mathrm{P}_{\mathrm{r}}$ value of $54 \mu \mathrm{C} / \mathrm{cm}^{2}$ for highly (117) oriented thin film. The vector of the self or spontaneous polarization $\left(\mathrm{P}_{\mathrm{s}}\right)$ for $\mathrm{Bi}_{4} \mathrm{Ti}_{3} \mathrm{O}_{12}$ falls in the ac-plane and forms an angle of $\sim 4.5$ degrees with the $a$-axis, and therefore, the highly (117) oriented thin films show much greater $\mathrm{P}_{\mathrm{r}}$. As for the KBT, its spontaneous polarization vector is closer to the $a$-axis or $b$-axis than the $c$-axis, and therefore, the highly $c$-axis oriented thin films

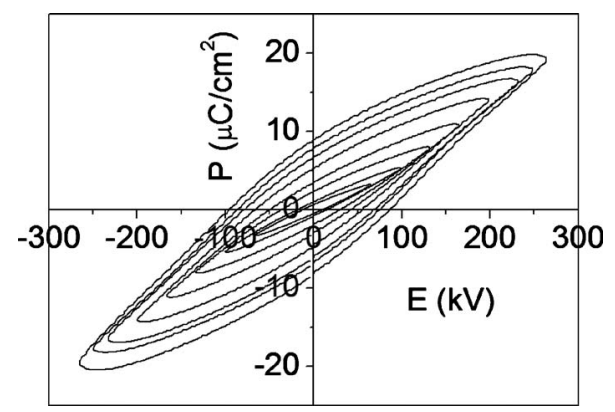

FIG. 3. P-E hysteresis loops of the Pt/KBT/Pt thin film capacitor memory element, measured at different maximum applied voltages and a frequency of $100 \mathrm{~Hz}$. 

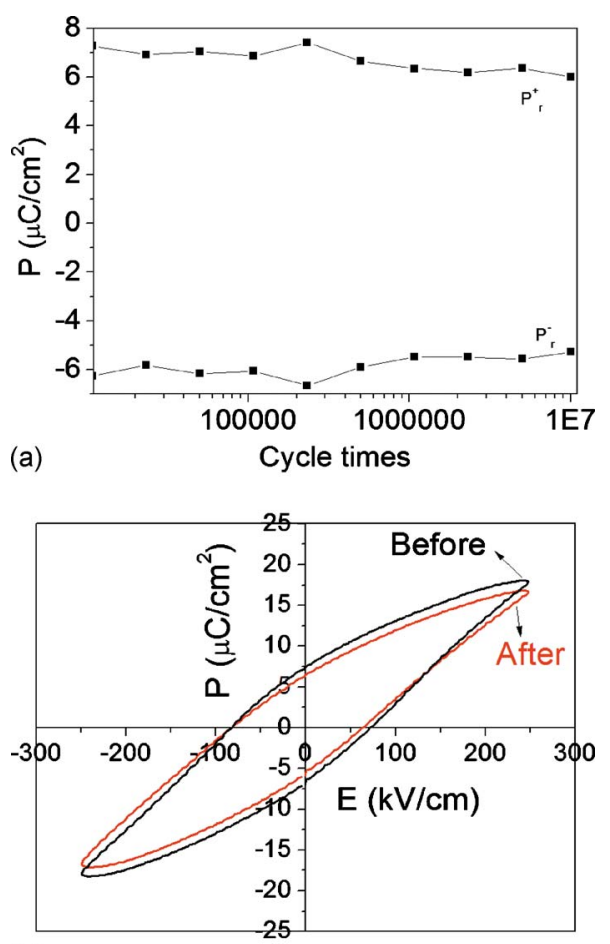

(b)

FIG. 4. (Color online) (a) Electrical fatigue characteristics of Pt/KBT/Pt capacitor. (b) The P-E loops before fatigue testing and after the test. The polarization measurement is at $15 \mathrm{~V}$, the switching voltage is $12 \mathrm{~V}$, and the frequency is $5 \mathrm{kHz}$.

show much less polarization than the single crystal samples measured in the $a$ direction or $b$ direction. The other reason for the observed big difference in their polarization values is that the value obtained in this study is from a sample that is far from being saturated in P-E measurements.

Fatigue measurements of the Pt/KBT/Pt thin film capacitor are shown in Fig. 4(a). The polarization of the capacitor shows little change after switching $10^{7}$ times. The initial value of $2 \mathrm{P}_{\mathrm{r}}$ is $14 \mu \mathrm{C} / \mathrm{cm}^{2}$, the final value after $10^{7}$ switches is $12 \mu \mathrm{C} / \mathrm{cm}^{2}$, and the decrease is about $14.5 \%$. The fatigue resistance behavior is less than that of $\mathrm{Sm}$ doped $\mathrm{Bi}_{4} \mathrm{Ti}_{3} \mathrm{O}_{12}$. The P-E loops before and after fatigue measurements are also plotted for comparison [Fig. 4(b).]

Figure 5 shows the dielectric permittivity and loss of the KBT thin film memory element in the form of a Pt/KBT/Pt capacitor. The dielectric permittivity decreases with increasing frequency, while the loss increases monotonically. How-

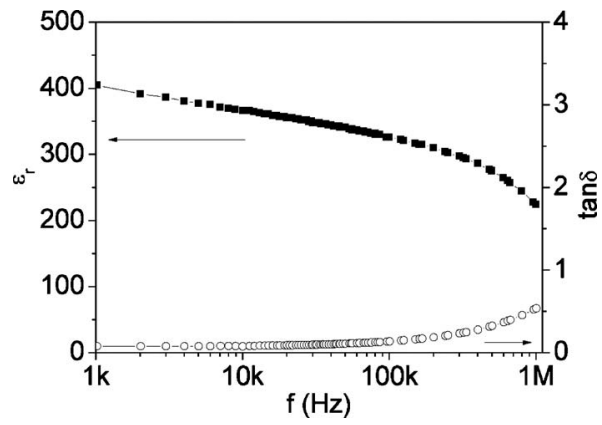

FIG. 5. Dielectric permittivity and loss of the KBT thin film in the form of a Pt/KBT/Pt capacitor.

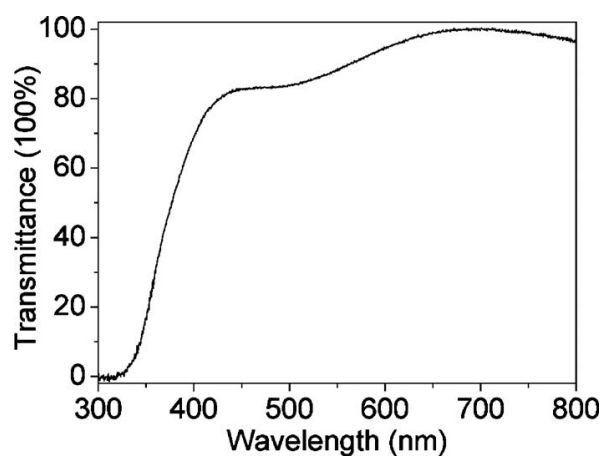

FIG. 6. Normalized transmittance spectrum of KBT film on fused quartz substrate in wavelength from 300 to $800 \mathrm{~nm}$. The oscillations in transmittance come from the interference due to reflection from the top surface of the film and the interface between the film and the substrate.

ever, there is no sudden change in their values up to $1 \mathrm{MHz}$. All these results indicate that the observed P-E hysteresis behavior in the KBT capacitor originates mainly from the ferroelectric polarization switching of bound charges. The dielectric permittivity at $200 \mathrm{kHz}$ is 327 , and the loss is $15 \%$. Both the value of the dielectric permittivity and the loss are greater than the values for a ceramic KBT capacitor. It is proposed here that the higher value of the dielectric permittivity is caused by the less insulating nature of the samples, since the leakage current during the dielectric measurement contributes significantly to the observation of dielectric permittivity. The higher loss of the thin film in comparison to the ceramic sample means that there is a higher density of dislocations or charge centers in the films. This is probably caused by oxygen vacancies and the high volatility of bismuth and potassium.

Figure 6 shows the transmittance spectra of a KBT thin film on fused quartz glass substrate in a wavelength range from 300 to $800 \mathrm{~nm}$. It was found that the absorption edge of KBT film is at $343 \mathrm{~nm}$, which corresponds to a band gap, $\mathrm{E}_{\mathrm{g}}$, of $3.6 \mathrm{eV}$. The band gap of the KBT is greater than that of $\mathrm{Bi}_{4} \mathrm{Ti}_{3} \mathrm{O}_{12}$, which is about $3.2 \mathrm{eV}$. ${ }^{16}$ The larger band gap indicates that KBT has higher intrinsic resistance, which favorites ferroelectric applications in terms of higher breakdown voltage and reduced electric leakage. Such a difference in band gap between KBT with $\mathrm{m}=4$ and $\mathrm{Bi}_{4} \mathrm{Ti}_{3} \mathrm{O}_{12}$ with $\mathrm{m}$ $=3$ can be explained on the basis of the lower electronegativity of the potassium ion compared to the bismuth ion.

\section{CONCLUSIONS}

In summary, lead-free KBT thin film was fabricated by the PLD method. The thin film shows a strongly preferred growth habit along its $c$-axis. This highly $c$-axis oriented thin film capacitor shows a remanent polarization of about $10 \mu \mathrm{C} / \mathrm{cm}^{2}$. However, higher polarization values could be achieved in $a$-axis or $b$-axis oriented thin film capacitors, although this will be a great challenge for film fabrication due to the layered structure and strong growth habit along the $c$-axis. The band gap is greater than that of $\mathrm{Bi}_{4} \mathrm{Ti}_{3} \mathrm{O}_{12}$, indicating that KBT should have higher intrinsic breakdown voltage and resistance. Doping with rare earth elements might be very useful to enhance its ferroelectric properties in 
terms of increased polarization and reduced dielectric loss for better memory performance, as with $\mathrm{Bi}_{4} \mathrm{Ti}_{3} \mathrm{O}_{12}$.

\section{ACKNOWLEDGMENTS}

The project was supported by an ARC Future Fellowship (Grant No. FT0990391) and a Discovery project (Project No. DP0987190). We would like to thank Dr. Tania Silver for careful reading of this paper.

${ }^{1}$ B. Aurivillius, Ark. Kemi 1, 499 (1950).

${ }^{2}$ H. X. Yan, H. T. Zhang, R. Ubic, M. J. Reece, J. Liu, Z. J. Shen, and Z. Zhang, Adv. Mater. 17, 1261 (2005).

${ }^{3}$ B. H. Park, B. S. Kang, S. D. Bu, T. W. Noh, J. Lee, and W. Jo, Nature (London) 401, 682 (1999).

${ }^{4}$ U. Chon, H. M. Jang, M. G. Kim, and C. H. Chang, Phys. Rev. Lett. 89, 087601 (2002).

${ }^{5}$ Z. X. Cheng, X. L. Wang, S. X. Dou, K. Ozawa, and H. Kimura, Appl.
Phys. Lett. 90, 222902 (2007).

${ }^{6}$ T. Kojima, T. Sakai, T. Watanabe, H. Funakubo, K. Saito, and M. Osada, Appl. Phys. Lett. 80, 2746 (2002).

${ }^{7}$ Z. X. Cheng, C. V. Kannan, K. Ozawa, H. Kimura, and X. L. Wang, Appl. Phys. Lett. 89, 032901 (2006)

${ }^{8}$ C. A. P. de Araujo, J. D. Cuchiaro, L. D. Mcmillan, M. C. Scott, and J. F. Scott, Nature (London) 374, 627 (1995).

${ }^{9}$ Y. Noguchi, M. Miyayama, K. Oikawa, and T. Kamiyama, J. Appl. Phys. 95, 4261 (2004).

${ }^{10}$ K. Yamamoto, Y. Kitanaka, M. Suzuki, M. Miyayama, Y. Noguchi, C. Moriyoshi, and Y. Kuroiwa, Appl. Phys. Lett. 91, 162909 (2007).

${ }^{11}$ K. Kato, K. Suzuki, D. S. Fu, K. Nishizawa, and T. Miki, Appl. Phys. Lett. 81, 3227 (2002).

${ }^{12}$ H. Irie and M. Miyayama, Appl. Phys. Lett. 79, 251 (2001).

${ }^{13}$ H. Irie, M. Miyayama, and T. Kudo, J. Appl. Phys. 90, 4089 (2001).

${ }^{14}$ C. M. Wang and J. F. Wang, J. Am. Ceram. Soc. 91, 918 (2008).

${ }^{15}$ Y. Noguchi, M. Suzuki, Y. Kitanaka, S. Teranishi, and M. Miyayama, Appl. Phys. Lett. 93, 032904 (2008).

${ }^{16}$ C. V. Kannan, Z. X. Cheng, H. Kimura, and A. Miyazaki, Jpn. J. Appl. Phys., Part 1 45, 835 (2006) 